\title{
Ossification of Ligamentum Flavum in Middle East Arabs: A Hospital-Based Study
}

\author{
Khaled Al-Jarallah $^{\mathrm{a}}$ Osama Al-Saeed $^{\mathrm{b}}$ Diaa Shehab $^{\mathrm{a}}$ Khaledah Dashti $^{\mathrm{c}}$ \\ Mehraj Sheikh ${ }^{b}$
}

Departments of a Medicine and ${ }^{\mathrm{b}}$ Radiology, Faculty of Medicine, Kuwait University, Jabriya, and

cMinistry of Health, Jabriya, Kuwait

\begin{abstract}
Key Words
Ossification • Ligamentum flavum • Posterior longitudinal

ligament $\cdot$ Magnetic resonance imaging $\cdot$ Cervical spine
\end{abstract}

Arab population. OLF should be kept in mind if a patient presents with radiculopathy, particularly in the cervical region, for which surgical intervention is contemplated.

Copyright $\odot 2012$ S. Karger AG, Basel

\begin{abstract}
Objective: To investigate the frequency of ossification of the ligamentum flavum (OLF) in the spine among the Arab population in Kuwait using magnetic resonance imaging (MRI) surveillance of the whole spine. Subjects and Methods: A consecutive series of 102 patients with low back pain were recruited from the outpatient clinic of Mubarak Al-Kabeer Hospital, Kuwait. MRI of the whole spine in the sagittal plane was obtained in at least two sequences $\left(T_{1}\right.$ and $\left.T_{2}\right)$. The OLF was defined as low signal intensity thickening of the ligament in both $T_{1}$ and $T_{2}$ sequences on the posterior margin of the spinal canal, causing indentation of the theca with or without cord compression. Results: Of the 102 cases, 19 (18.6\%) patients had OLF. Of the 19 positive cases, $12(63.2 \%)$ were present at a single level, and 7 (36.8\%) at multiple levels. A total of 26 OLF segments were identified in the following anatomical distribution: cervical: 15 (57.7\%); upper thoracic (T1-T4): 1 (3.8\%); mid thoracic (T5-T8): 4 (15.4\%); lower thoracic (T9-T12): 4 (15.4\%), and lumbar region: 2 (7.7\%). Of the 19 OLF patients, $2(10.5 \%)$ had tandem ossification of the posterior longitudinal ligament in the cervical spine and were symptomatic. Conclusions: The frequency of OLF appears to be high among this hospital-based cohort of the
\end{abstract}

\section{Introduction}

Ossification of the ligamentum flavum (OLF) has been recognized as a cause of spinal cord compression. Most of the OLF remains asymptomatic and any vertebral segments can be involved [1]. However, identifying this pathology is important as its clinical implication, when symptomatic, may need urgent surgical intervention. Clinicians as well as radiologists should be aware of this entity which should not be overlooked. The epidemiology and etiology of OLF remains obscure. OLF has been reported exclusively in the Far East, mostly in Japan [2]; there are scattered case reports among Caucasians [3], people of African descent [4], Arabs [5], Chinese [6] and in French Antilles [7]. The reported studies on the prevalence of OLF are limited by their sample size, region of the spine imaged and the method of diagnosis. The examination of the whole spine using $\mathrm{T}_{2}$-weighted sagittal magnetic resonance imaging (MRI) scan is the sequence of choice for screening the longitudinal extent of OLF [8]. In this prospective study, we conducted MRI surveillance of the whole spine among Arab patients in Kuwait.

\section{KARGER}

Fax +4161306 1234

E-Mail karger@karger.ch

www.karger.com
(C) 2012 S. Karger AG, Basel

1011-7571/12/0216-0529\$38.00/0

Accessible online at:

www.karger.com/mpp
Dr. Khaled Al-Jarallah

Medicine Department

Faculty of Medicine

PO Box 24923, Safat 13110 (Kuwait)

Tel. +965 2531 9596, E-Mail aljarallah@ @sc.edu.kw 
Fig. 1. a Sagittal $\mathrm{T}_{2}$-weighted MRI image of the cervical spine showing focal low signal thickening of the flavum ligament at C4-5 and C5-6 levels (arrows) on the posterior margin of the spinal canal, causing indentation of the theca. $\mathbf{b}$ Axial $\mathrm{T}_{2}$ weighted MRI image at C5-6 levels shows the thickened right flavum ligament (arrow). c Axial CT image at C5-6 level confirms the ossification (arrow) of the thickened flavum ligament.
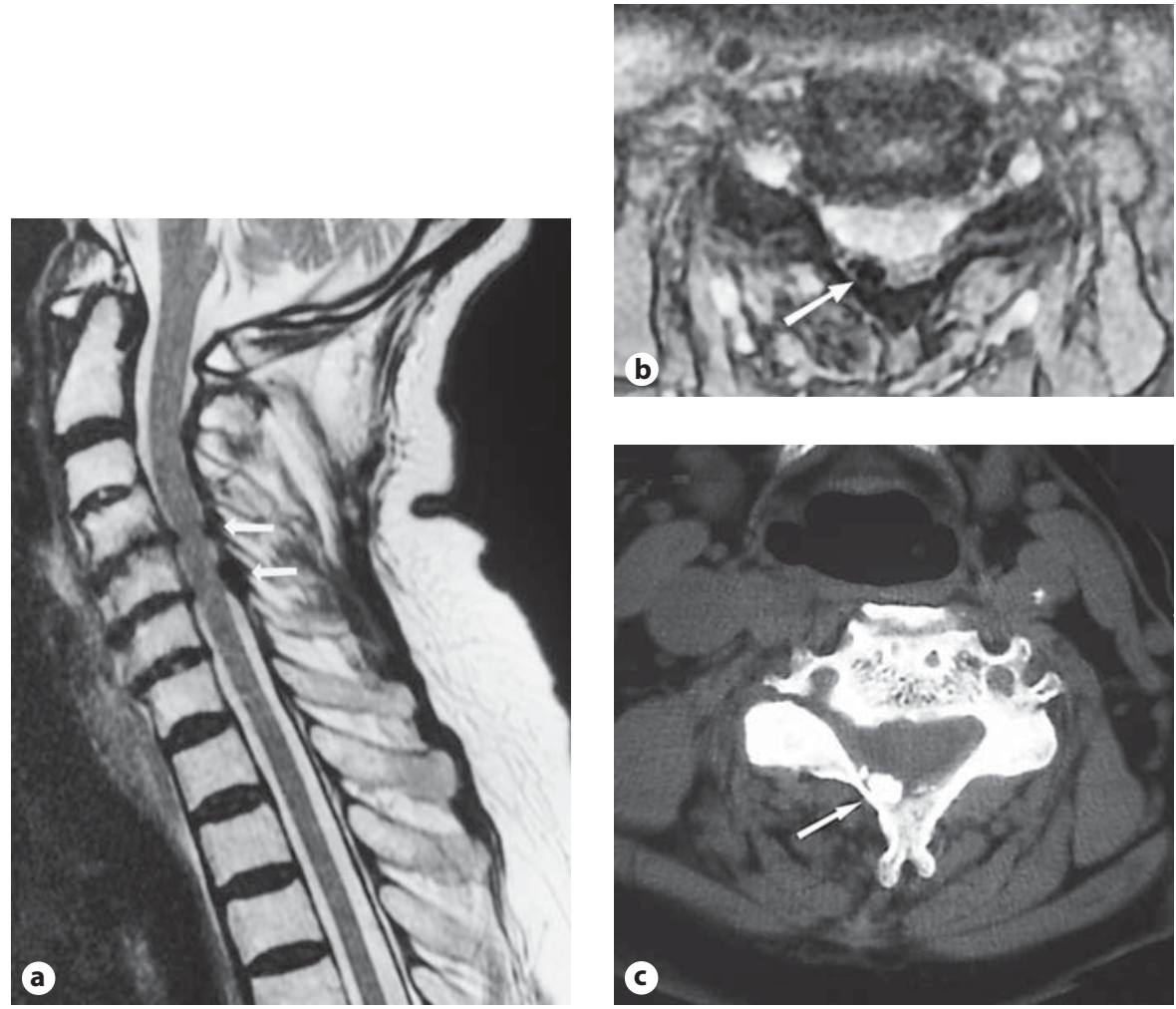

Table 1. Demographic features of patients with OLF

\begin{tabular}{|c|c|c|c|c|}
\hline Variables & $\begin{array}{l}\text { OLF } \\
(\mathrm{n}=14)\end{array}$ & $\begin{array}{l}\text { OLF+OPLL } \\
(\mathrm{n}=5)\end{array}$ & $\begin{array}{l}\text { Total } \\
(\mathrm{n}=19)\end{array}$ & $\begin{array}{l}\mathrm{p} \\
\text { value }\end{array}$ \\
\hline \multicolumn{5}{|l|}{ Gender } \\
\hline Male & $7(50.0 \%)$ & $4(80.0 \%)$ & $11(57.9 \%)$ & \\
\hline Female & $7(50.0 \%)$ & $1(20.0 \%)$ & $8(42.1 \%)$ & $0.267^{\mathrm{a}}$ \\
\hline \multicolumn{5}{|l|}{ Age, years } \\
\hline Mean \pm SD & $52.8 \pm 11.5$ & $52.2 \pm 10.0$ & $53.2 \pm 11.0$ & $0.797^{\mathrm{b}}$ \\
\hline$<50$ years & $5(35.7 \%)$ & $2(40.0 \%)$ & $7(36.8 \%)$ & $0.634^{\mathrm{a}}$ \\
\hline$>50$ years & $9(64.3 \%)$ & $3(60.0 \%)$ & $12(63.2 \%)$ & \\
\hline \multicolumn{5}{|l|}{ Diabetes } \\
\hline Present & $6(42.9 \%)$ & 0 & $6(31.6 \%)$ & $0.111^{\mathrm{a}}$ \\
\hline Absent & $8(57.1 \%)$ & $5(100 \%)$ & $13(68.4 \%)$ & \\
\hline
\end{tabular}

${ }^{\mathrm{a}} \chi^{2}$ test. ${ }^{\mathrm{b}}$ Independent samples $\mathrm{t}$ test.

\section{Subjects and Methods}

\section{Participants}

A consecutive series of patients evaluated for low back pain from the outpatient clinic of Mubarak Al-Kabeer Hospital in Hawalli district (population 698,753) in Kuwait (population $3,328,136$ ) were invited to participate in the study in the year 2010. All 102 participants were of Arab nationalities from the Middle
East. MRI scanning of the whole spine was used to evaluate these patients. Patients with previous spinal surgery, inflammatory arthritis, patients with contraindication to MRI and those who declined to participate $(n=16)$ were excluded from the study. The study was approved by the Committee for the Protection of $\mathrm{Hu}$ man Subjects in Research in Health Science Centre, Kuwait University.

\section{Radiological Examination}

MRI scanning of the entire spine in at least 2 sequences $\left(\mathrm{T}_{1}\right.$ and $\mathrm{T}_{2}$ ) was performed in 102 patients (males: 57, females: 45 ) in Mubarak Al-Kabeer Hospital using a 1.5-tesla MRI system (General Electric Medical System, Milwaukee, Wisc., USA). Sagittal $\mathrm{T}_{1}$-weighted and $\mathrm{T}_{2}$-weighted fast spin-echo sequences (TR, 3,325 $\mathrm{ms}$; TE, $85 \mathrm{~ms}$; slice thickness, $5 \mathrm{~mm}$ ) were used to image the whole spine. All the MRIs were read blindly by two experienced radiologists (D.K., M.S.) separately and differences were settled by consensus. All the scans were evaluated for the presence of OLF and the posterior longitudinal ligament (OPLL). OLF was defined as low signal intensity thickening of the ligament in both $\mathrm{T}_{1}$ and $\mathrm{T}_{2}$ sequences on the posterior margin of the spinal canal, causing indentation of the theca with or without cord compression (fig. 1a, b). A complementary CT scan of the region was performed to confirm ossification (fig. 1c). OLF, if present, was further classified by the pattern of involvement as the isolated type: lesions involving lamina; the continuous type: continuous lesion along 2 or more lamina, and the noncontinuous type: isolated or continuous at intervals as previously described [6]. Patients with OLF were analyzed for tandem ossification of OPLL. 
Table 2. Clinical and radiological features of patients with OLF

\begin{tabular}{|c|c|c|c|c|c|c|}
\hline \multirow[t]{2}{*}{ Patient } & \multirow[t]{2}{*}{ Age/sex } & \multirow{2}{*}{$\begin{array}{l}\text { Coexisting } \\
\text { conditions }\end{array}$} & \multicolumn{2}{|c|}{ MRI findings } & \multirow{2}{*}{$\begin{array}{l}\text { Tandem } \\
\text { ossification }\end{array}$} & \multirow[t]{2}{*}{ Symptoms } \\
\hline & & & spinal level & segments & & \\
\hline 1 & $56 / \mathrm{F}$ & - & $\mathrm{C} 4 / 5$ & single & OLF & - \\
\hline 2 & $63 / \mathrm{M}$ & asthma & $\mathrm{C} 4 / 5, \mathrm{C} 5 / 6$ & multiple & $\mathrm{OLF}+\mathrm{OPLL}$ & radicular pain \\
\hline 3 & $66 / \mathrm{M}$ & - & C6 & single & $\mathrm{OLF}+\mathrm{OPLL}$ & radicular pain \\
\hline 4 & $57 / \mathrm{M}$ & $\mathrm{DM}$ & $\mathrm{C} 4 / 5, \mathrm{C} 5 / 6$ & multiple & OLF & - \\
\hline 5 & $44 / \mathrm{F}$ & Crohn's & $\mathrm{T} 10 / \mathrm{T} 11$ & single & OLF & - \\
\hline 6 & $73 / \mathrm{M}$ & $\mathrm{DM}$ & T9 & single & OLF & - \\
\hline 7 & $35 / \mathrm{M}$ & - & $\mathrm{T} 4, \mathrm{~L} 4$ & multiple & OLF & - \\
\hline 8 & $34 / \mathrm{M}$ & - & $\mathrm{C} 6 / 7$ & single & OLF & - \\
\hline 9 & $56 / \mathrm{M}$ & $\mathrm{DM}$ & $\mathrm{C} 5$ & single & OLF & - \\
\hline 10 & $54 / \mathrm{F}$ & $\mathrm{DM}$ & $\mathrm{C} 5 / 6$ & single & OLF & - \\
\hline 11 & $43 / \mathrm{F}$ & - & $\mathrm{C} 5$ & single & $\mathrm{OLF}+\mathrm{OPLL}$ & - \\
\hline 12 & $43 / \mathrm{F}$ & - & T6 & single & OLF & - \\
\hline 13 & $69 / \mathrm{F}$ & - & $\mathrm{T} 12$ & single & OLF & - \\
\hline 14 & $63 / \mathrm{M}$ & - & $\mathrm{T} 10, \mathrm{~L} 4$ & multiple & $\mathrm{OLF}$ & - \\
\hline 15 & $57 / \mathrm{F}$ & $\mathrm{DM}$ & $\mathrm{T} 8$ & single & OLF & - \\
\hline 16 & $53 / \mathrm{M}$ & - & C5, C6 & multiple & $\mathrm{OLF}+\mathrm{OPLL}$ & - \\
\hline 17 & $47 / \mathrm{M}$ & - & C5, C6 & multiple & $\mathrm{OLF}+\mathrm{OPLL}$ & - \\
\hline 18 & $56 / \mathrm{M}$ & $\mathrm{DM}$ & C5, T9 & multiple & OLF & - \\
\hline 19 & $43 / \mathrm{F}$ & - & $\mathrm{T} 8$ & single & OLF & - \\
\hline
\end{tabular}

$\mathrm{DM}=$ Diabetes mellitus; $\mathrm{C}=$ cervical $\mathrm{T}=$ thoracic $\mathrm{L}=$ lumbar.

\section{Analysis}

The data were analyzed using the Statistical Package for Social Sciences version 17.0. Categorical variables were compared by $\chi^{2}$ test and mean values of continuous variables were compared by independent samples $t$ test. A value of $\mathrm{p}<0.05$ was considered to be statistically significant.

\section{Results}

The average age of the 102 patients was 53.2 years (range 34-75). The demographic features of the patients (age, gender, coexisting conditions) as well as associated symptoms and MRI findings are shown in tables 1 and 2, respectively.

Of the 102 patients, 19 (18.6\%) were identified to have OLF (11 males and 8 females). Of the 19 patients with OLF, 12 (63.2\%) had OLF at a single level, whereas 7 (36.8\%) showed OLF at multiple levels. A total of 26 OLF segments were identified to be affected in the following anatomical distribution: in the cervical region: 15 (57.7\%); upper thoracic: 1 (3.8\%); mid thoracic (T5-T8): 4 (15.4\%); lower thoracic (T9-T12): 4 (15.4\%), and lumbar region: 2 (7.7\%), as shown in figure 2 . Of the 19 cas- es, only $2(10.5 \%)$ had symptoms concordant with the level of OLF and both had cervical OLF along with tandem OPLL and presented with symptoms of cervical radiculopathy.

\section{Discussion}

OLF, also known as ossification of the yellow ligament, is considered to be a recognized cause of myeloradiculopathy since it was first reported by Polgar [1] in 1920. The epidemiological data on OLF is limited, but from the available literature a wide regional as well as racial variation of OLF was reported. Regarding the gender ratio, except for 3 studies which showed a higher rate of OLF in female patients $[5,9]$, most studies have shown a male preponderance [10-12]. In our study there was no significant gender difference.

The prevalence of OLF in our study was $18.6 \%$ and the cervical spine was the most common site (57.7\%) followed by the thoracic region (34.6\%). The disease appears to be endemic in Japan from where most of the studies are reported with prevalence ranging from 4.5 to $8.6 \%$ based on analysis of plain radiographs $[9,13,14]$. All these stud- 


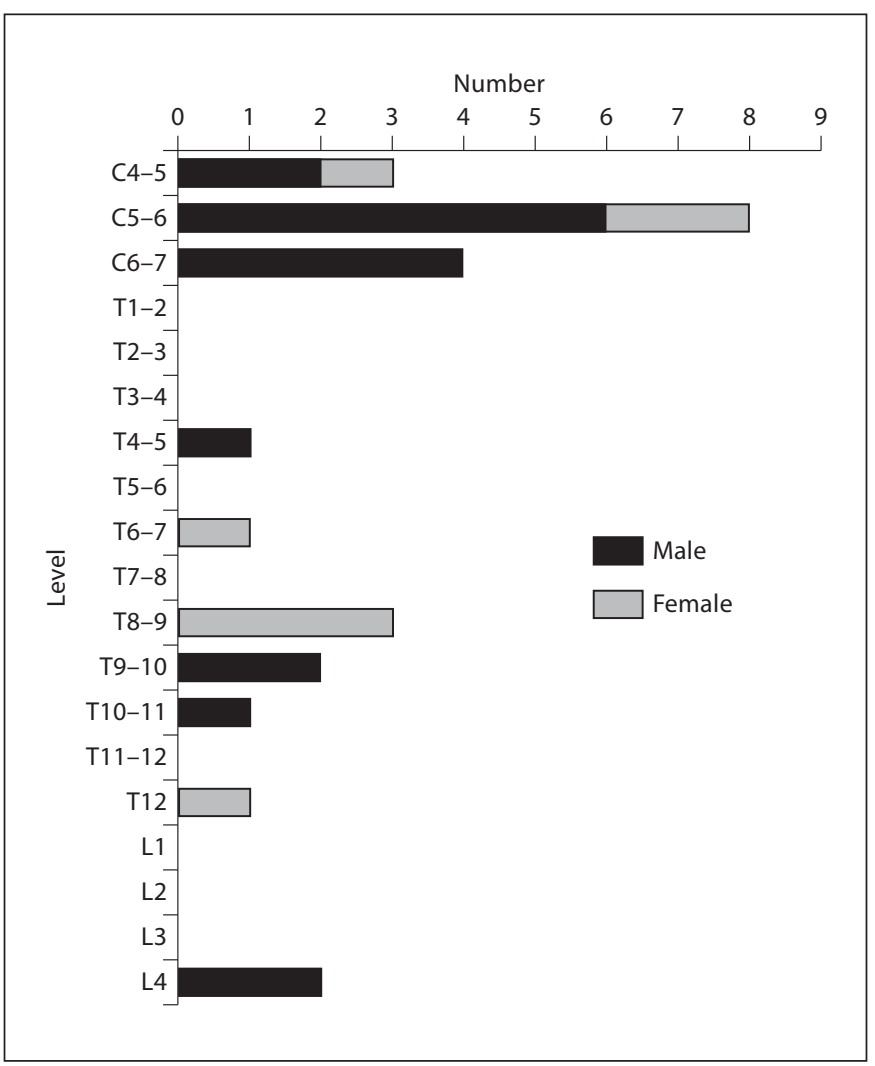

Fig. 2. Distribution of OLF sites between genders.

ies were large studies with 1,058-2,403 subjects and the prevalence was lower than our findings, as the plain X-ray is expected to have less sensitivity. This lack of sensitivity is due to the fact that the radiopaque shadow representing OLF can be obscured by superimposed bony structures [15] unlike CT/MRI scans which by virtue of cross-sectional imaging can eliminate superimposed structures and clearly identify the areas of ossification $[16,17]$. The frequency of $18.6 \%$ OLF of this study using MRI was lower than the $26 \%$ of the study in the USA [13] and $35.5 \%$ in Saudi Arabia [15] using CT. However, a study from China using MRI of the whole spine reported a prevalence of only $3.8 \%[6]$.

The differences in these studies could be explained as follows. MRI has the distinct advantage of imaging the whole spine in the sagittal plane and therefore can assess the spine for multiple-level lesions [8]. The $\mathrm{T}_{2}$-weighted sagittal MRI image is the sequence of choice for screening the longitudinal extent of OLF, evaluating potential spinal cord involvement and identifying multiple level lesion [15]. On MRI the flavum ligament in the diseased state (hypertrophied, ossified or calcified) is shown as a low signal intensity lesion in the posterior aspect of the spinal canal on $\mathrm{T}_{1}, \mathrm{~T}_{2}$, and proton density-weighted MR images [18]. OLF is recognized by the presence of a triangular or hemispheric area of low signal intensity at the level of the posterior margin of the canal $[11,13,14,18-20]$. Because the ligamentum flavum is thinnest in the midline, OLF is usually more evident in parasagittal MRI images [6]. Our study revealed that $37 \%$ had OLF at multiple levels, $33 \%$ of which were of noncontinuous type.

OLF can coexist with OPLL which then aggravates radiculopathy as well as myelopathy $[3,9,21,22]$. Guo et al. [23] conducted a systematic review and observed that the most common pattern of tandem ossification was OLF of the thoracic spine with cervical OPLL. Based on the analysis of the published data, the authors classified findings into concurrent, nonconcurrent, and mixed types, based on the pattern of whether OPLL and OFL were at the same levels. In our study the 5\% coexistence of OLF and OPLL (concurrent) were cervical OPLL with cervical OLF conforming with type 1 according to the classification of Guo et al. [23]. No association between coexisting conditions and the presence of OLF or OPLL was found in our study group. This was not unexpected as OLF is usually asymptomatic especially when lesions are small as was observed in our study where the majority of patients with OLF were incidentally noted at sites remote from their symptoms. The 2 patients that were symptomatic in our study presented with cervical radiculopathy and were found to have OLF and OPLL in the cervical region with severe encroachment on both the dorsal and the ventral epidural space. It may be noted that it is the noncontinuous type of OLF that is prone to be missed and this can have serious consequences. There have been reports of thoracic paraplegia developing after lumbar decompressive surgery due to stenosis and spinal cord compression from missed OLF in the thoracic spine [4]. A third of our subjects had OLF at multiple levels, with a third of these being of the noncontinuous type. Hence we recommend that surveillance of the whole spine should be done prior to any surgical intervention.

\section{Conclusion}

The frequency of OLF appears to be high among the hospital-based cohort of the Arab population. OLF should be kept in mind if the patient presents with radiculopathy, particularly in the cervical region, for which surgical intervention is contemplated. 


\section{References}

1 Polgar F: Über interakuelle Wirbelverkalkung. Fortschr Geb Röntgenstr Nuklearmed Ergänzungsbd 1920;40:292-298.

-2 Kudo S, Ono M, Russell WJ: Ossification of thoracic ligamenta flava. Am J Roentgenol 1983;141:117-121.

3 Parekh HC, Gurusinghe NT, Perera SS, Prabhu SS: Ossification of the ligamentum flavum in a Caucasian: case report. Br J Neurosurg 1993;7:678-690.

4 Pascal-Mousselard H, Samdja D, Cabre P, Raynaud M, Catonne Y: Ossification of ligamenta flava with severe myelopathy in a black patient: a case report. Spine 1998;23: 1607-1608.

5 Al-Orainy IA, Kolawole T: Ossification of the ligamentum flavum. Eur J Radiol 1998; 29:76-82.

-6 Guo JJ, Kuk K, Karppinen J, Yang H, Cheung KM: Prevalence, distribution and morphology of ossification of the ligamentum flavum. Spine 2010;35:51-56.

-7 Pascal-Mouselard H, Cabre P, Smadja, Catonné Y: Symptomatic ossification of the ligamentum flavum: a clinical series from the French Antilles. Spine 2005;30:E400-E405.

-8 Sugimura H, Kakitsubata Y, Suzuki Y, Kakitsubata S, Tamura S, Uwada O, Kodama T, Yano T, Watanabe K: MRI of ossification of ligamentum flavum. J Comput Assist Tomogr 1992;16:73-76.

-9 Kurihara A, Tanaka Y, Tsumura N, Iwasaki Y: Hyperostotic lumbar canal stenosis. A review of 12 surgically treated cases with roentgenographic survey of ossification of the yellow ligament at the lumbar spine. Spine 1988;13:1308-1316.
10 Aizawa T, Sato T, Tanaka Y, Ozawa H, Hoshikawa T, Ishii Y, Morozumi N, Ishibashi K, Kasama F, Hyodo H, Murakami E, Nishihira T, Kokubun S: Thoracic myelopathy in Japan: epidemiological retrospective study in Miyagi prefecture during 15 years. Tohoku J Exp Med 2006;210:199-208.

11 He S, Hussain N, Li S, Hou T: Clinical and prognostic analysis of ossified ligamentum flavum in a Chinese population. J Neurosurg Spine 2005;3:348-354.

12 Ben Hamouda K, Jemel H, Haouet S, Khaldi M: Thoracic myelopathy caused by ossification of the ligamentum flavum: a report of 18 cases. J Neurosurg Spine 2003;99:157-161.

3 Williams DM: Ossification in the cephalic attachments of the ligamentum flavum: an anatomical and CT study. Radiology 1984; 150:423-426.

14 Kuh SU, Kim YS, Cho YE, Jin BH, Kim KS, Yoon YS, Chin DK: Contributing factors affecting the prognosis surgical outcome for thoracic OLF. Eur Spine J 2006;15:485-491.

15 Saiki K, Hattori A, Kawai S, Miyamoto T, Tsue K, Kotani H: The ossification of the yellow ligament in the thoracic spine: incidence, classification, neurological finding and narrow spinal canal. Orthop Surg Traumatol (Jpn) 1981;24:191-199.
16 Takeuchi A, Miyamoto K, Hosoe H, Shimizu $\mathrm{K}$ : Thoracic paraplegia due to missed thoracic compressive lesions after lumbar spinal decompression surgery. Report of three cases. J Neurosurg Spine 2004;100:71-74.

17 Miyazawa N, Akiyama I: Ossification of the ligamentum flavum of the cervical spine. J Neurosurg Spine 2007;51:139-144.

18 Xiong L, Zeng QY, Jinkins JR: CT and MRI characteristics of ossification of the ligamentum flava in the thoracic spine. Eur Radiol 2001:11:1798-1802.

19 Fong SY, Wong HK: Thoracic myelopathy secondary to ligamentum flavum ossification. Ann Acad Med Singapore 2004;33:340 346.

$20 \mathrm{Li} \mathrm{F}$, Chen Q, Xu K: Surgical treatment of 40 patients with thoracic ossification of the ligamentum flavum. J Neurosurg Spine 2006; 191-197.

21 Tomita K, Kawahara N, Baba H, Kikuchi Y, Nishimura H: Circumspinal decompression for thoracic myelopathy due to combined ossification of the posterior longitudinal ligament and ligamentum flavum. Spine 1990; 15:1114-1120.

22 Enomoto H, Kuwayama N, Katsumata T, Doi T: Ossification of the ligamentum flavum. A case report and its MRI finding. Neuroradiology 1988;30:571-573.

-23 Guo JJ, Yang HL, Cheung KM, Tang TS, Luk DK: Classification and management of the tandem ossification of the posterior longitudinal ligament and flaval ligament. Chin Med J 2009;122:219-224. 